Brit. F. vener. Dis. (1970) 46, 205

\title{
Experience with a rapid direct immunofluorescent test for the gonococcus as a 'bench' procedure in venereal disease clinics
}

\author{
THE LATE R. A. HENDERSON, S. RUTHERFORD, J. A. PHELPS, AND P. ROBERTSON \\ From the Black Street Clinic and the Special Clinic, Southern General Hospital, Glasgow
}

Since Deacon, Peacock, Freeman, Harris, and Bunch (1960) reported on the application of fluorescent antibody (FA) staining methods in the diagnosis of gonorrhoea, such procedures have been widely adopted, but for the most part performance of the tests has been confined within laboratories. This paper reports the experiences of male nurses and technicians with a rapid direct immunofluorescent test used as a 'bench' procedure in venereal diseases clinics.

The principal indication for this type of test is in the detection of gonococci in the secretions of women nominated as contacts of men proved to be infected. In such cases Gram-stained smears taken at the first visit may prove negative; this was so in the cases of 21 per cent. of such women seen recently in Glasgow clinics; and by the time positive results to cultures are known, some women may already have defaulted. The direct fluorescent antibody staining method described by Gallwey, Nicol, and Ridley (1967) required 55 minutes of preparation before microscopy, an unreasonable time for a patient to wait at the clinic after failure of diagnosis by Gram-stained smears.

The direct method evolved by Sommerville (1968) is rapid, but his laboratory technique was felt to be too sophisticated for use during a busy V.D. clinic session. This technique has accordingly been modified as follows:

\section{OPTICAL APPARATUS}

A Gillett and Seibert I.Q. Fluorescence microscope is used with $\times 10$ achromatic and $\times 55$ fluorite objectives and $a \times 6$ Huygenian eyepiece. The light source is an Iodine Quartz lamp and a widefield condenser is used for darkfield examination. The exciting filter is made up of Kodak-Wratten 38A and 32 gelatin filters; the barrier filter is a Kodak-Wratten 12 gelatin filter.

Received for publication June 23, 1969

Correspondence to Mr S. A. Rutherford, The Clinic, 67 Black Street, Glasgow, C.4
ANTISERA

Rabbit anti-gonococcal serum conjugated with fluorescein isothiocyanate is obtained in powder form from Difco Laboratories and rehydrated with $5 \mathrm{ml}$. distilled water. To this is added $5 \mathrm{mg}$. Naphthaline Black counterstain obtained from Messrs. Gurr. Fluorescein free immersion oil is supplied by Wild Ltd.

\section{Method}

Duplicate thin urethral and cervical smears are taken from all new female patients at their first visit. These smears are fixed by heat and one set is examined after Gramstaining; if the Gram-stained smears fail to reveal $N$. gonorrhoeae, the duplicate smears are sent to the male clinic for FA staining.

\section{PREPARATION OF FA STAINED SMEARS}

(1) When the slides are received at the male clinic a ring is engraved round small portions of the urethral and cervical smears and the slides are further fixed in 3 per cent. formol saline for 3 minutes.

(2) The slides are then washed gently in tap water (Glasgow tap water is soft and relatively pure), patted dry with a tissue, warmed to complete drying, and allowed to cool.

(3) A small amount of stain is applied to the ringed portion of the smears using a platinum loop.

(4) Slides are then incubated in a moist (supersaturated) chamber at $37^{\circ} \mathrm{C}$. for 10 minutes.

(5) Excess stain is gently washed off with tap water, and the slide is patted dry with a tissue and warmed to complete drying.

\section{CONTROLS}

With each batch of slides is included one slide each from stocks prepared from known cases of gonorrhoea and nonspecific urethritis in male patients. These act as controls on the amount of fluorescence to expect. The stain deteriorates in time, even when kept at $4^{\circ} \mathrm{C}$. in a refrigerator and some batches of stain deteriorate more quickly than others.

The specificity of the test was checked by examining smears of $N$. catarrhalis and $N$. meningitidis kindly supplied by Dr. R. V. Fallon of Ruchill Hospital; specific 
fluorescence did not occur. During this study there were eleven occasions on which coagulase positive Staph. aureus was grown on culture of genital secretions; smears from these cases showed no fluorescence.

The results presented are those obtained by us while working in the Glasgow clinics. Duplicate slides taken at the female clinics were stockpiled for later examination when time permitted. We have compared the results by cases because, in the purely routine procedures at the City Laboratory, urethral and cervical cultures are not both pursued provided that one is positive.

\section{Results}

Table I shows the results of Gram-stained smears and cultures in 74 cases in which the Rapid FA test showed gonococci. Smears and cultures were both positive in 41 , and cultures alone positive in seventeen, making a total of 58 (a 78 per cent. agreement with the fluorescent test). A further ten smears were positive when cultures were negative, making 51 positive smears in all (69 per cent. agreement). In six cases ( 8 per cent.) both smears and cultures were negative.

TABLE I Results obtained by Gram-stained smears and cultures in 74 cases in which gonorrhoea was diagnosed by the Rapid FA test (percentages in parenthesis)

\begin{tabular}{|c|c|c|c|c|}
\hline \multirow{2}{*}{\multicolumn{2}{|c|}{ Gram stain }} & \multicolumn{3}{|l|}{ Culture } \\
\hline & & \multirow{2}{*}{$\begin{array}{l}\text { Positive } \\
41 \\
17\end{array}$} & \multirow{2}{*}{ 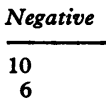 } & \multirow{2}{*}{$\begin{array}{l}\text { Total } \\
51(69) \\
23(31)\end{array}$} \\
\hline Smears & $\begin{array}{l}\text { Positive } \\
\text { Negative }\end{array}$ & & & \\
\hline & Total & $58(78)$ & $16(22)$ & 74 \\
\hline
\end{tabular}

Table II shows the results of Gram-stained smears and cultures in 74 cases when the Rapid FA test was negative. It was a chance event that at the time we were collecting the material for this contribution there were equal numbers of positive and negative findings by means of the Rapid FA test. In three cases both smears and cultures were positive and, while on no occasion was the culture alone positive, smears alone were positive in six cases. There was agreement between all three tests in 65; the Rapid FA test therefore correlated with cultures in 96 per cent. and with smears in 88 per cent. of cases.

TABLE II Results obtained by Gram-stained smears and cultures in 74 cases in which the Rapid FA test was negative (percentages in parenthesis)

\begin{tabular}{|c|c|c|c|c|}
\hline \multirow{2}{*}{\multicolumn{2}{|c|}{ Gram stain }} & \multicolumn{3}{|l|}{ Culture } \\
\hline & & \multirow{2}{*}{$\begin{array}{l}\text { Positive } \\
3 \\
0\end{array}$} & \multirow{2}{*}{$\frac{\text { Negative }}{6}$} & \multirow{2}{*}{$\frac{\text { Total }}{9(12)}$} \\
\hline Smears & $\begin{array}{l}\text { Positive } \\
\text { Negative }\end{array}$ & & & \\
\hline & Total & $3(4)$ & $71(96)$ & 74 \\
\hline
\end{tabular}

Table III demonstrates the degree of correlation between the three methods of diagnosis. It was closest between the Rapid FA test and culture (82 per cent.), followed by the FA test and smears (78.4 per cent.), and lastly with our established method of diagnosis, smears and cultures (77.7 per cent.). In fact, there was correlation between all three methods in 71.6 per cent. of the 148 cases. The results of the Rapid FA test correlated better with those from either smears or cultures than the latter did together.

TABLE III Agreement or disagreement between the three methods of diagnosis in 148 cases (percentages in parenthesis)

\begin{tabular}{|c|c|c|c|c|}
\hline \multirow{2}{*}{ Methods under comparison } & \multicolumn{2}{|c|}{ Agreement } & \multicolumn{2}{|c|}{ Disagreement } \\
\hline & No. & Per cent. & No. & Percent. \\
\hline Rapid FA test and culture & 129 & $87 \cdot 2$ & 19 & $12 \cdot 8$ \\
\hline Rapid FA test and smears & 116 & $78 \cdot 4$ & 32 & $21 \cdot 6$ \\
\hline Culture and smears & 115 & $77 \cdot 7$ & 33 & $22 \cdot 3$ \\
\hline All three methods & 105 & $71 \cdot 6$ & 43 & $28 \cdot 4$ \\
\hline
\end{tabular}

Comparison can be made by site of the results of the Rapid FA test and of Gram-stained smears. Table IV compares the findings of both in specimens from the urethra and the cervix.

TABLE IV Comparison of findings of Gram-stained smears and Rapid FA test by site (percentages in parenthesis)

\begin{tabular}{|c|c|c|c|c|}
\hline \multirow{2}{*}{ Site } & \multirow{2}{*}{$\begin{array}{l}\text { Gram- } \\
\text { stained } \\
\text { smear }\end{array}$} & \multicolumn{2}{|c|}{ Rapid $F A$ test } & \multirow{2}{*}{ Total } \\
\hline & & Positive & Negative & \\
\hline \multirow{3}{*}{ Urethra } & Positive & 39 & 7 & $46(31)$ \\
\hline & Negative & 29 & 73 & $102(69)$ \\
\hline & Total & $68(46)$ & $80(54)$ & 148 \\
\hline \multirow{3}{*}{ Cervix } & Positive & 42 & 14 & $56(38)$ \\
\hline & $\overline{\text { Negative }}$ & 20 & 72 & $92(62)$ \\
\hline & Total & $62(42)$ & $86(58)$ & 148 \\
\hline
\end{tabular}

With the urethral smears the procedures agree in 39 positive cases and 73 negative; a further seven were positive in Gram-stained smears, making 46 (31 per cent.) in all. The Rapid FA test revealed a further 29 positive cases, 68 (46 per cent.) in all.

With cervical smears both methods agreed in 42 positive and 72 negative cases. Gram-stained smears alone were positive in fourteen, making 56 (38 per cent.) in all. The Rapid FA test alone was positive in twenty, a total of 62 (42 per cent.). 
It is to be noted that the Rapid FA test gave 46 per cent. positive results in the urethral specimens and only 42 per cent. positive results in the cervical specimens. With Gram-stained smears on the other hand, 31 per cent. of those from the urethra and 38 per cent. of those from the cervix were positive.

\section{Discussion}

With this technique we found that the Rapid FA test is at least as specific as the other methods in current use. On six occasions the test gave positive results when Gram-stained smears and cultures were negative; three of these were certainly false positives and the other three were from cases of known contacts of gonorrhoea, but further tests could not be carried out. The chances of making a false diagnosis are minimized if use of the test is limited to known contacts when the initial Gram-stained smears have not revealed gonococci.

In three cases the Rapid FA test was negative and the routine smears and cultures were positive, but as the Gram-stained smears were positive these specimens would not usually have been sent for fluorescence testing, nor would they in the other six cases in which Gram-stained smears alone were positive. In all, there was very close correlation when the Rapid FA test was negative, and overall there was closer correlation between results of the Rapid FA test and the other two methods separately than there was between results of Gram-stained smears and cultures.

Table IV shows that the Rapid FA test gave a larger yield of positive results in urethral smears than in cervical smears, whereas Gram-staining revealed more positive findings in smears from the cervix than from the urethra. Our ratio of positive FA test results to Gram-stained smear results was $1.5: 1$ in the urethra and $1.1: 1$ in the cervix, but the findings of Gallwey, Nicol, and Ridley (1967) were more definite, namely $2 \cdot 2: 1$ in the urethra and $1 \cdot 1: 1$ in the cervix.

The method of staining is simple, but it is essential that none of the stain should dry out on the slide, which then becomes unreadable because of nonspecific fluorescence.

The criteria for the microscope, its light source, and the filters are even more exacting than for ordinary dark ground microscopy, and routine cleaning and maintenance must be of the highest standard.

Those carrying out this type of microscopy need considerable experience; scrutiny of at least fifty cervical and fifty urethral slides is required before any operator becomes competent, and while he is learning his results with the first two or three dozen are full of inaccuracies, usually false positives. Smears, particularly from the cervix, must be thin to reduce chances of non-specific fluorescence. Less fluorescence should be expected from intracellular than from extracellular gonococci. Operators must accustom themselves to a magnification lower than that usually employed for Gram-stained smears; once trained, however, they should take no longer to examine an FA-stained smear than a Gram-stained smear. Prolonged searching is not usually needed and tends to increase the incidence of false positives.

This account of our experience in the Glasgow clinics is designed to show that the Rapid FA staining method is a sensitive and accurate addition to conventional diagnostic procedures in the detection of gonorrhoea in female contacts.

\section{Summary}

A staining technique, based on that described by Sommerville (1968) for the direct immunofluorescent identification of $N$. gonorrhoeae, but modified for use by male nurses in venereal disease clinics, is described. This fluorescent antibody (FA) staining method is now in regular use in Glasgow clinics for supplementing Gram-stained smears and cultures in the diagnosis of gonorrhoea in cases of known female contacts, patients who are notoriously liable to default before culture results are available.

The specificity and sensitivity appear to be satisfactory, there being a good correlation with conventional methods and a greater positive yield from FA-stained smears than from Gram-stained smears. The method has proved practicable as a 'bench' procedure for use by male nurses and technicians during busy clinic sessions.

Our thanks are due to the Boards of Management of the Glasgow Northern Hospitals and Glasgow South-Western Hospitals and to the Western Region Hospital Board for their faith in allocating funds for the purchase of the microscopes before we could prove that they would be of service in the V.D. clinics, to Mr. Swan of Gillett and Seibert Ltd. for his help and interest, to Dr. R. G. Sommerville for his continued interest and forbearance over a long period, and without whose research the whole project would have failed, and finally to our chief $\mathrm{Dr}$. C. B. S. Schofield, M.D., M.R.C.P., for permission to publish this paper.

\section{References}

Deacon, W. E., Peacock, W. L., Jr., Freeman, E. M., Harris, A., and Bunch, W. L., JR. (1960) Publ. Hlth Rep. (Wash.), 75, 125

Gallwey, J. M. D., Nicol, C. S., and Ridley, $M$. (1967) Brit. F. vener. Dis., 43, 168

Sommerville, R. G. (1968) Bull. Wld Hlth Org., 39, 942 
Emploi d'une épreuve d'immuno-fluorescence indirecte rapide comme procédé de détection, sur 'Paillasse', du gonocoque dans les cliniques vénéréologiques

SOMMAIRE

On décrit une technique de coloration fondée sur celle décrite par Sommerville (1968) pour l'identification de $N$. gonorrhoeae par immuno-fluorescence directe, mais modifiée pour pouvoir être employée par les infirmiers des cliniques vénéréologiques. Cette coloration fluorescente de l'anticorps (FA) est maintenant employée d'une manière régulière dans les cliniques de Glasgow à titre de complément de la coloration au Gram et des cultures, pour le diagnostic de la gonococcie chez des femmes connues comme contacts et notoirement susceptibles de disparaître avant que les résultats de la culture soient disponibles.

La spécificité et la sensibilité se montrent satisfaisantes, en bonne corrélation avec les méthodes conventionnelles, et l'on obtient un plus grand pourcentage de positivité sur les lames colorées par fluorescence par rapport à celles colorées au Gram. La méthode s'est montrée practicable comme procédé de "paillasse" pouvant être employé par les infirmiers et les techniciens lors de séances cliniques chargées. 